\title{
Selection of Metalloporphyrin Heme Oxygenase Inhibitors Based on Potency and Photoreactivity
}

\author{
HENDRIK J. VREMAN, BRADLEY C. EKSTRAND, AND DAVID K. STEVENSON \\ Division of Neonatal and Developmental Medicine, Department of Pediatrics, Stanford University School of \\ Medicine. Stanford. California 94305
}

\begin{abstract}
The heme oxygenase inhibitor, tin protoporphyrin, is being studied for the prevention of neonatal jaundice. This potential drug, however, is also a photosensitizer that could cause serious and unknown side effects when administered to newborns. Therefore, we have developed in vitro and in vivo procedures for the screening and further characterization of potentially safe heme oxygenase inhibitors. The ideal inhibitor: 1) contains a biocompatible metal, 2) is not degraded in tissues, 3 ) is a highly potent inhibitor of heme oxygenase, and 4) does not participate in photochemical reactions. Proto- and mesoporphyrin derivatives with the tin, zinc, manganese, chromium, nickel, and magnesium were screened in vitro for suitability. Chromium protoporphyrin and mesoporphyrin were further studied in vitro and in vivo and were found to meet the ideal criteria. Chromium mesoporphyrin appeared to be the most potent in vitro inhibitor of adult Wistar rat tissue heme oxygenase. Four $\mu \mathrm{mol}$ of chromium protoporphyrin or chromium mesoporphyrin/kg body weight, administered intraperitoneally to adult male Wistar rats given a heme load through intraperitoneal administration of $30 \mu \mathrm{mol}$ heme/kg body weight, caused significant suppression of hemolysis-induced increase in carbon monoxide production to 72 and $44 \%$ of control, respectively, $5.5 \mathrm{~h}$ after treatment. At $\mathrm{t}=6 \mathrm{~h}$, the tissue heme oxygenase activity, measured in vitro, was significantly reduced to 33 and $<5 \%$ in liver and to 22 and $<5 \%$ in spleen after the administration of chromium protoporphyrin and mesoporphyrin, respectively, but was not reduced in brain. The results show that there exist effective metalloporphyrin heme oxygenase inhibitors without photosensitizing properties. (Pediatr Res 33: 195-200, 1993)
\end{abstract}

\section{Abbreviations}

CO, carbon monoxide

VeCO, total body $\mathrm{CO}$ excretion

HO, heme oxygenase

CrPP, chromium protoporphyrin

CrMP, chromium mesoporphyrin

MnPP, manganese protoporphyrin

NiPP, nickel protoporphyrin

SnPP, tin protoporphyrin

SnMP, tin mesoporphyrin

PP, protoporphyrin

MP, mesoporphyrin

Received March 1992; accepted October 7. 1992

Correspondence and reprint requests: David K. Stevenson, M.D., Department of Pediatrics, Stanford University School of Medicine, Stanford, CA 94305-5119.

Supported by National Institutes of Health Grant HD14426 and the Burroughs Wellcome Company.

Patent disclosure: Hendrik J. Vreman, Ph.D. and David K. Stevenson. M.D. have been issued U.S. Patent No. 4,831,024 for Method to Prevent Neonatal Jaundice, involving a screening procedure to detect elevated bilirubin production by $\mathrm{CO}$ detection technology combined with metalloporphyrin therapy.
Physiologic jaundice is still being considered a risk factor during the neonatal period. The phenomenon results from the abrupt cessation of bilirubin clearance by the placenta and a transient deficiency in hepatic bilirubin removal. It is exacerbated by the increased rate of bilirubin production in the neonate, which is 2- to 3 -fold greater than that of the adult. Several factors and conditions further increase this rate (1). In particular, hemolytic disease such as $\mathrm{ABO}$ and $\mathrm{Rh}$ incompatibility cause significant elevation in total body bilirubin production rates, as indexed by $\mathrm{CO}$ excretion rates (2). Markedly elevated serum bilirubin concentrations have been associated with neurotoxicity (3).

Although the risk factor of moderately elevated serum bilirubin levels $[<20 \mathrm{mg} / \mathrm{dL}(342 \mu \mathrm{mol} / \mathrm{L})]$ in term well babies without hemolysis is being questioned (4), there is less doubt that hyperbilirubinemia in premature infants and in those with hemolytic disease may be deleterious. Traditionally, jaundice is treated through removal of accumulated bilirubin by phototherapy or blood-exchange transfusion (5). A potentially more effective and preventive treatment may be the inhibition of bilirubin production through administration of a specific inhibitor of HO (EC 1.14.99.3), the rate-limiting enzyme in the bilirubin production pathway from heme $(6,7)$. Synthetic analogs of heme, especially the tin and zinc derivatives of PP and MP, have been studied for this purpose $(7-11)$. SnPP has been shown to retard the development of human neonatal hyperbilirubinemia (8). However, the tin metalloporphyrins have also been shown to be potent photosensitizers capable of producing singlet oxygen (12), which can oxidize a large number of organic molecules, including membrane lipids, energy metabolites, proteins, and nucleic acids $(13,14)$. The destruction of some of these compounds may be responsible for the mortality observed in neonatal rats treated with photosensitizing metalloporphyrins and subsequently exposed to visible light $(15,16)$.

Because the potentially serious side effects of this photoreactivity have been incompletely studied, we have developed the following criteria and procedures for identification of metalloporphyrins potentially suitable for treatment of human neonatal hyperbilirubinemia. The ideal inhibitor: 1 ) contains a metal that occurs naturally in the body or is harmless in trace amounts, 2) is not degraded in tissue to possibly harmful substances, 3) can effectively inhibit $\mathrm{HO}$ at relatively low $(<40 \mu \mathrm{mol} / \mathrm{kg})$ doses, and 4) does not participate in photodestructive reactions. In this study, we investigated several synthetic metalloporphyrins with manganese, chromium, nickel, and magnesium as central metals. The HO-inhibiting and metabolic characteristics of some of these compounds have been studied by others (7, 17-19). Results with heme, tin, and zinc porphyrins were included for comparison. The evaluation of these metalloporphyrins consisted of a screening phase followed by a more in-depth examination of promising compounds. 


\section{MATERIALS AND METHODS}

Materials. Metalloporphyrins (Porphyrin Products, Inc., Logan, UT) were each dissolved in $500 \mu \mathrm{L}$ of $10 \%$ (wt/vol) ethanolamine. After addition of $7 \mathrm{~mL}$ of distilled water and adjusting the $\mathrm{pH}$ to 7.4 with $20-\mu \mathrm{L}$ aliquots of $1 \mathrm{~N} \mathrm{HCl}$, the volume was adjusted to $10 \mathrm{~mL}$ to obtain solutions of $650 \mu \mathrm{M}$ concentration. Metalloporphyrin solutions for determination of in vivo efficacy were made up to $6 \mathrm{mM}$. The metalloporphyrins studied included proto and meso derivatives (PP and MP, respectively) of iron, tin, zinc, manganese, chromium, nickel, and magnesium por-

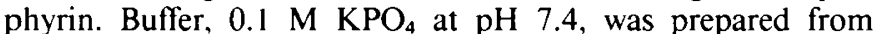
$\mathrm{KH}_{2} \mathrm{PO}_{4}, \mathrm{KOH}$ and distilled water. All procedures involving metalloporphyrin and bilirubin solutions were carried out under near-dark conditions.

Animals. This protocol was approved by the research committee of the Stanford University Division of Laboratory Animal Medicine. Animal care and use were in accord with guidelines established by the National Institutes of Health. Adult male Wistar rats (Simonsen Laboratories, Inc., Gilroy, CA), weighing 275 to $325 \mathrm{~g}$ were used as the source of $\mathrm{HO}$ and as a hemolytic model for the in vivo efficacy testing of metalloporphyrins. These rats were fasted for $16 \mathrm{~h}$ before the beginning of any experiment, but had unlimited access to water and were housed in a temperature-controlled room $\left(25 \pm 1^{\circ} \mathrm{C}\right)$ with a 12-h light cycle. Neonatal Wistar rat litters (Simonsen) 12 to $24 \mathrm{~h}$ of age, were used for the in vivo phototoxicity test. The pups had unlimited access to the fed mother until the beginning of the test. All animals were killed by decapitation at the end of each experiment.

HO assay. Tissue $\mathrm{HO}$ activity was determined with a gas chromatographic assay (20). For the in vitro screening procedure, fasting adult male Wistar rat livers were collected, rinsed, and immediately homogenized with a Biohomogenizer (Biospec Products, Inc., Bartlesville, KY) in four volumes of ice-cold buffer. The homogenate was centrifuged at $13000 \times g$ for 15 min. The HO activity in the supernatant was determined by measuring the amount of $\mathrm{CO}$ generated by the enzyme from 50 $\mu \mathrm{M} / 11.2 \mu \mathrm{M}$ methemalbumin in the presence of $1.5 \mathrm{mM}$ $\mathrm{NADPH}$ at $37^{\circ} \mathrm{C}$ in the dark. In vitro inhibition potential of metalloporphyrins was determined by addition of small volumes of metalloporphyrin to the reaction medium $(40 \mu \mathrm{M}$ for the screening procedure and $0.1-40 \mu \mathrm{M}$ for the in vitro efficacy experiments). The ability of administered metalloporphyrins to inhibit organ HO activity in vivo was determined in the same manner. Tissues used for this purpose were harvested from the same animals used to study metalloporphyrin effects on the in vivo bilirubin production rates ( $\mathrm{VeCO}$, see below). $\mathrm{HO}$ activity is expressed in terms of $\mathrm{nmol} \mathrm{CO}$ produced $/ \mathrm{h} / \mathrm{mg}$ protein.

Metalloporphyrin metabolism assay. In vitro metabolism of metalloporphyrins was determined by substituting equimolar amounts of metalloporphyrin $(50 \mu \mathrm{M})$ for the heme in the $\mathrm{HO}$ assay. Traditionally, metabolism like that observed with heme is defined as the $\mathrm{CO}$ production by a tissue preparation from the substrates under study in the presence of NADPH minus that produced in the absence of NADPH.

Protein determination. The protein concentration of tissue preparations was determined by the method of Lowry et al. (21), using BSA as standard.

$V e C O$. Intraperitoneal heme loading of fasted adult male Wistar rats was used as an iatrogenic model of hyperbilirubinemia. The ability of metalloporphyrins to suppress this exaggerated bilirubin production was determined by measuring the decrease of $\mathrm{VeCO}(22)$. Each rat was weighed and then placed in a Plexiglas tube $(26 \times 5.5 \mathrm{~cm}$ inner diameter, $690 \mathrm{~mL})$, supplied with a measured CO-free air flow at approximately $110 \mathrm{~mL} /$ $\mathrm{min}$. After a 1- to 2-h equilibration period, the $\mathrm{CO}$ in the chamber outlet gas was determined by gas chromatography $(\mathrm{t}=0 \mathrm{~h})$. Each rat was then given an intraperitoneal injection of $30 \mu \mathrm{mol}$ heme/ $\mathrm{kg}$ body weight. In addition, experimental rats were given $4 \mu \mathrm{mol}$ metalloporphyrin $/ \mathrm{kg}$ body weight, and the control rats received an equal volume of metalloporphyrin solvent. The animals were returned to their chambers, and the $\mathrm{VeCO}$ was determined every half hour for $6 \mathrm{~h}$. At the completion of this procedure, animals were decapitated and the tissue HO activity was determined (see above).

In vitro photoreactivity. Photoreactive compounds have been found to photooxidize organic compounds to yield CO (14). $\mathrm{NADH}$, like NADPH, is one of the compounds that are particularly sensitive to degradation by this process. For this study, we determined the photoreactivity of metalloporphyrins in vitro by incubating $40 \mu \mathrm{M}$ metalloporphyrin in $60 \mu \mathrm{L}$ of $4.5 \mathrm{mM} \mathrm{NADH}$ (Sigma Chemical Co., St. Louis, MO) at $37^{\circ} \mathrm{C}$ in clear, septumsealed vials $(2 \mathrm{~mL})$. The vials were then exposed to cool white light $\left(20 \mu \mathrm{W} \cdot \mathrm{cm}^{-2} \cdot \mathrm{nm}^{-1}\right.$ or $30 \mathrm{~W} \cdot \mathrm{m}^{-2}$, see below $)$ for $15 \mathrm{~min}$. The generated $\mathrm{CO}$ was quantitated by injecting the vial headspace gas into a reduction gas analyzer (Trace Analytical, Inc., Menlo Park, CA). The results, corrected for dark control reactions determined simultaneously, were expressed in terms of pmol CO generated per vial per 15 -min period.

In vivo phototoxicity. In vivo phototoxicity of the chromium and manganese metalloporphyrins was assessed as described earlier (15). Metalloporphyrins at a dose of $40 \mu \mathrm{mol} / \mathrm{kg}$ body weight were administered to each of 12 - to 24 -h-old neonatal Wistar rats. Animals were placed three to a glass chamber $(25 \times$ $2.5 \mathrm{~cm}$ inner diameter) supplied with $\mathrm{CO}$-free air at $100 \pm 5$ $\mathrm{mL} / \mathrm{min}$. The chambers were placed for $12 \mathrm{~h}$ over a bank of four cool white fluorescent light tubes $\left(20 \mathrm{~W}\right.$ each, $20 \mu \mathrm{W} \cdot \mathrm{cm}^{-2}$. $\mathrm{nm}^{-1}$ or $30 \mathrm{~W} \cdot \mathrm{m}^{-2}$ ). The temperature was maintained at $30 \pm$ $1^{\circ} \mathrm{C}$ with circulating air. The survival rate after $12 \mathrm{~h}$ of light exposure was taken as an index of phototoxicity. Animals treated with $30 \mu \mathrm{mol} \mathrm{SnPP} / \mathrm{kg}$ were used as positive controls.

Bilirubin degradation. Photoreactive metalloporphyrins also enhance the photodegradation of bilirubin (23). Twenty-five $\mu \mathrm{L}$ of $18 \mathrm{mg}(30.8 \mu \mathrm{mol})$ bilirubin dissolved in $100 \mathrm{~mL} 4 \%$ (wt/vol) human serum albumin solution in $2-\mathrm{mL}$ clear reaction vials were incubated at $37^{\circ} \mathrm{C}$ with $40 \mu \mathrm{M}$ metalloporphyrin for 30 min over cool white light $\left(20 \mu \mathrm{W} \cdot \mathrm{cm}^{-2} \cdot \mathrm{nm}^{-1}\right.$ or $\left.30 \mathrm{~W} \cdot \mathrm{m}^{-2}\right)$. After completing the reaction, $1 \mathrm{~mL}$ of buffer was added, and the bilirubin concentration in the solution was measured with the spectrophotometric UB analyzer, UA-1 (Arrows Co., Ltd., Osaka, Japan). Photodegradative loss of bilirubin was expressed as a percentage of dark controls and compared with bilirubin degradation in the absence of metalloporphyrin (light control).

Light measurements. Radiance $\left(\mu \mathrm{W} \cdot \mathrm{cm}^{-2} \cdot \mathrm{nm}^{-1}\right)$ was measured with a Mark II Bili-Meter (Olympic Medical, Seattle, WA) over the range of 425 to $475 \mathrm{~nm}$. Light intensities were also determined with a model $2 \mathrm{M}$ thermopile detector with sapphire window and argon gas (Dexter Research Center, Dexter, MI). This detector has a flat spectral response from UV to far infrared and a linear signal output from $10^{-2}$ to $10^{3} \mathrm{~W} \cdot \mathrm{m}^{-2}$

Statistics. The data are presented as means $\pm \mathrm{SD}$. The results of $\mathrm{VeCO}$ measurements were tested using the one-way factorial analysis of variance. All other experiments were evaluated by repeated-measures analysis of variance. The Scheffe F-test was considered significant at $p<0.05$ as indicated by appropriate letters defined in each table and figure.

\section{RESULTS}

The results in Figure 1 show that, as expected, the reference compound, heme, served as the only effective substrate for the $\mathrm{HO}$ reaction. Of the other compounds tested, only the manganese porphyrins appeared to support observable but low-level $\mathrm{CO}$ production. However, the net $\mathrm{CO}$ production was due to suppression of $\mathrm{CO}$ production in the blank rather than an increase in $\mathrm{CO}$ production in the presence of NADPH, which is characteristic for $\mathrm{HO}$ substrates. Therefore, this $\mathrm{CO}$ production is not likely to be due to metabolism of the manganese porphyrins but is perhaps representative of an inhibitory effect on the as-yet- 


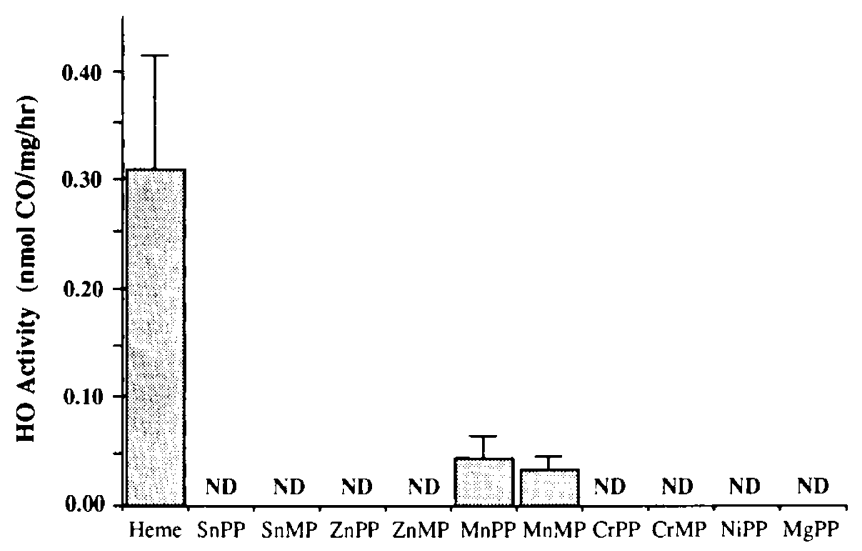

Fig. 1. Metalloporphyrins as substrates for rat liver HO. Postmitochondrial supernatants prepared from the livers of fasted adult male Wistar rats were incubated for $15 \mathrm{~min}$ at $37^{\circ} \mathrm{C}$ with $50 \mu \mathrm{M}$ of the indicated metalloporphyrin and $1.5 \mathrm{mM}$ of NADPH. CO generation was quantitated by gas chromatography. PP and MP represent the proto- and mesoporphyrin derivatives, respectively. The $\mathrm{HO}$ activity level for each of the synthetic metalloporphyrins was significantly different $(p<0.05)$ from the heme control but not from other metalloporphyrins $(n=5)$. $N D$, activity not detected: $Z n$. zinc; $M g$. magnesium; $S n$, tin; $M n$, manganese; $\mathrm{Cr}$, chromium; $\mathrm{Ni}$, nickel.

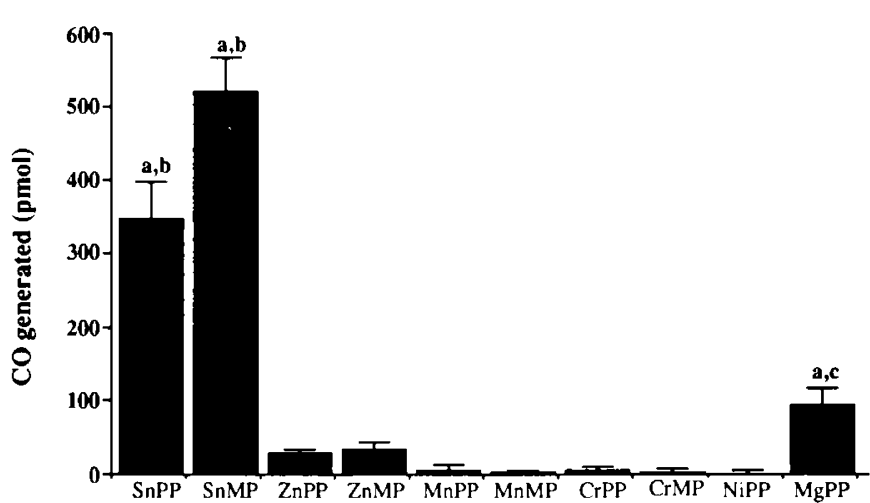

Fig. 2. Metalloporphyrin-supported photogeneration of $\mathrm{CO}$ from NADH. NADH $(4.5 \mathrm{mM})$ was incubated with $40 \mu \mathrm{M}$ of the indicated metalloporphyrin in sealed vials and exposed for $15 \mathrm{~min}$ at $37^{\circ} \mathrm{C}$ to cool white light $\left(20 \mu \mathrm{W} \cdot \mathrm{cm}^{-2} \cdot \mathrm{nm}^{-1}\right.$ or $\left.30 \mathrm{~W} \cdot \mathrm{m}^{-2}\right)$. $a$. Significantly different $(p<0.05)$ when compared with zero; $b$, when compared with all other compounds; and $c$, when compared with all other compounds except $\mathrm{ZnPP}$ and $\mathrm{ZnMP}(n=4)$.

unidentified minor process that is responsible for $\mathrm{CO}$ production in the absence of NADPH.

Figure 2 presents each metalloporphyrin's ability to photooxidize NADH and generate $\mathrm{CO}$. The reference tin analogs were the most powerful photooxidizers, with SnPP evolving $350 \mathrm{pmol}$ of $\mathrm{CO}$ and SnMP over $500 \mathrm{pmol}$ during the 15-min light exposure period. Magnesium porphyrin expressed only slight, but statistically significant, photoreactivity. Of the photoreactive porphyrins, the MP species appeared to be more reactive than the PP analogs, but the difference was not statistically significant. Zinc, manganese, chromium, and nickel compounds had no statistically significant photoreactivity as determined by this sensitive assay.

Figure 3 presents the results of another index of photoreactivity, the enhancement of bilirubin degradation. Light exposure alone decreased the bilirubin concentration in the bilirubin/ human serum albumin to $79 \%$ of dark control (dashed line). The presence of either SnPP or SnMP enhanced the effect of light exposure by decreasing the bilirubin concentration to $21 \%$ of dark control. Magnesium-PP was much less potent, decreasing the bilirubin concentration to $58 \%$. The two zinc compounds

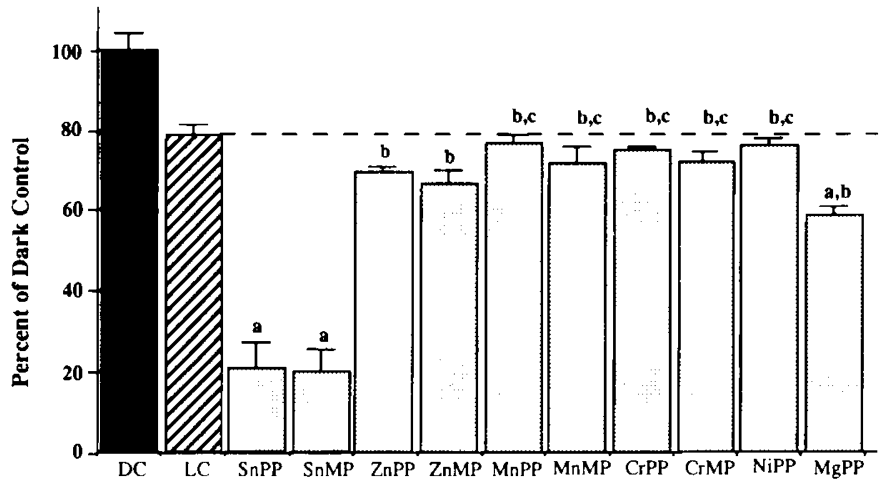

Fig. 3. Metalloporphyrin-enhanced photodegradation of bilirubin. Bilirubin/human serum albumin solutions $(18 \mathrm{mg} / 100 \mathrm{~mL})$ were incubated with $40 \mu \mathrm{M}$ of the indicated metalloporphyrin at $37^{\circ} \mathrm{C}$ and exposed for $30 \mathrm{~min}$ to cool white light $\left(20 \mu \mathrm{W} \cdot \mathrm{cm}^{-2} \cdot \mathrm{nm}^{-1}\right.$ or $\left.30 \mathrm{~W} \cdot \mathrm{m}^{-2}\right)$. After dilution with buffer, the remaining bilirubin was measured spectrophotometrically. $D C$, dark control, $L C$, light control (also indicated by the horizontal dashed line). LC and all compounds were significantly different from DC $(p<0.05)$. Compounds labeled with $a$ were significantly different from LC. Compounds labeled with $b$ were significantly different from SnPP and SnMP, and those labeled with $c$ were significantly different from MgPP.

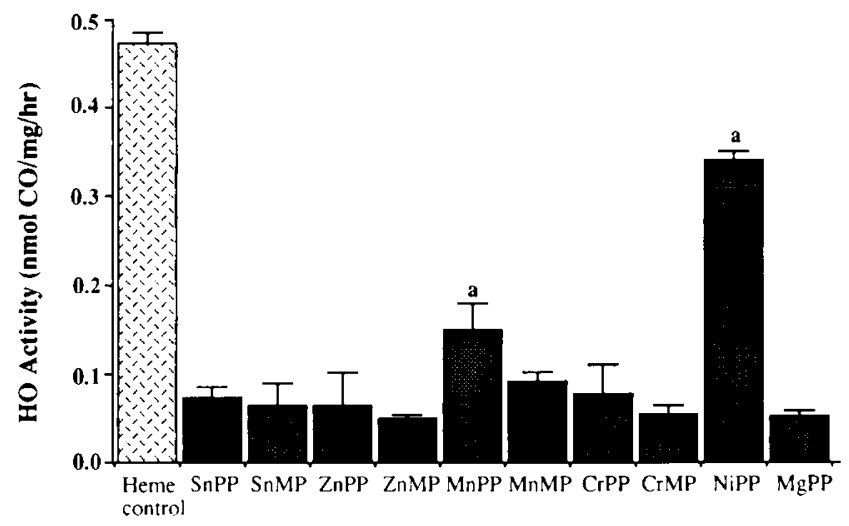

Fig. 4. Inhibition of $\mathrm{HO}$ with metalloporphyrins. Postmitochondrial supernatants prepared from the livers of fasted adult male Wistar rats were incubated with $40 \mu \mathrm{M}$ of the indicated metalloporphyrin and $\mathrm{HO}$ assay reagents for $15 \mathrm{~min}$ at $37^{\circ} \mathrm{C}$. The generated $\mathrm{CO}$. representing $\mathrm{HO}$ activity, was measured by gas chromatography. All compounds significantly $(p<0.05)$ inhibited the heme control reaction. Also significantly different were compounds labeled with $a$, when compared with all other inhibitors $(n=4)$.

only caused a decrease to about $67 \%$ of dark control. None of the other compounds significantly enhanced the photodegradation of bilirubin. These results parallel those found with the $\mathrm{CO}$ production assay shown in Figure 2.

When rat neonates were treated intraperitoneally with $40 \mu \mathrm{mol}$ each of CrPP, CrMP, MnPP, manganese mesoporphyrin, or SnPP, only the SnPP-treated animals suffered light-dependent death as has been shown previously $(15,16)$. These animals had symptoms as described previously and died within $4 \mathrm{~h}$ of the start of light exposure. None of the chromium- and manganeseporphyrin-treated animals died or showed any signs of observable adverse effects as described for SnPP (data not shown).

The ability of each metalloporphyrin to inhibit rat liver $\mathrm{HO}$ in vitro at the screening concentration of $40 \mu \mathrm{M}$ is illustrated in Figure 4. All metalloporphyrins inhibited $\mathrm{HO}$ activity to a significant extent. NiPP and MnPP were the least effective inhibitors in this series.

The results of the screening procedure indicated that the chromium metalloporphyrins were particularly attractive for further study. These compounds were not metabolized, did not 
cause photodestructive reactions, and potently inhibited HO. Therefore, we investigated the efficacy of CrPP and CrMP to inhibit rat liver and spleen $\mathrm{HO}$ in vitro over a range of concentrations. Furthermore, even though the manganese compounds appeared to have an effect on non-HO-related $\mathrm{CO}$ production, their total lack of photoreactivity made these compounds also attractive for some further in vitro efficacy study. Table 1 shows that there was significant, concentration-dependent inhibition at concentrations as low as $1 \mu \mathrm{M}$ for all four compounds. In the case of the chromium compounds, the MP appeared to be more potent. Spleen $\mathrm{HO}$ activity is more completely inhibited by all four compounds than is liver $\mathrm{HO}$ activity.

The chromium analogues were additionally tested for their ability to inhibit bilirubin production and tissue $\mathrm{HO}$ activity in vivo. The results of $\mathrm{CO}$ excretion rate experiments with an iatrogenic hemolytic model, using adult male Wistar rats, are shown in Figure 5. After injection of heme $(30 \mu \mathrm{mol} / \mathrm{kg}$ body weight), the $\mathrm{VeCO}$ of each animal began to increase significantly to reach approximately four times the control rate by $\mathrm{t}=4.5 \mathrm{~h}$. However, the steep rise in $\mathrm{VeCO}$ observed in control animals was less steep in the animals simultaneously given an intraperitoneal dose of $4 \mu \mathrm{mol} / \mathrm{kg}$ body weight of either CrPP or CrMP. As expected from the in vitro tests performed earlier, the CrMP was a more powerful inhibitor of $\mathrm{CO}$ production than $\mathrm{CrPP}$ ( significant only at $\mathrm{t}=6 \mathrm{~h}$ ), decreasing the maximum rate of $\mathrm{CO}$ production (recorded at $\mathrm{t}=5.5 \mathrm{~h}$ after heme administration) to 58 and $79 \%$ of the total excretion CO rate, respectively, or 44 and $72 \%$, respectively, of the $\mathrm{CO}$ excretion rate increase due to heme administration.

After $6 \mathrm{~h}$ of in vivo monitoring, the rats were killed and the livers, spleens, and brains were excised for determination of $\mathrm{HO}$ activity. As seen in Table 2 , the liver and spleen $\mathrm{HO}$ activity at $\mathrm{t}$ $=6 \mathrm{~h}$ after treatment was significantly lower in rats given either CrPP or CrMP. Again, the CrMP more potently inhibited HO than CrPP. However, the inhibitors did not appear to cross the blood-brain barrier, because no significant inhibition of brain HO was observed after the 6-h experimental time course.

\section{DISCUSSION}

The results of this investigation show that there exist effective synthetic metalloporphyrin $\mathrm{HO}$ inhibitors without photosensitizing properties. Thus, these compounds could be considered as alternative agents to the tin metalloporphyrins for suppressing the excessive neonatal jaundice often associated with hemolytic disease. Although phototoxicity is not likely to be the only side effect of these potential drugs, it remains one property that we believe may be significant to neonates receiving simultaneous light treatment. Several other side effects of metalloporphyrins have been reported (24), and the significance of these needs future attention.

The screening procedure also identified metalloporphyrins that were not metabolized to $\mathrm{CO}$ and other products that may be detrimental to the organism. Besides heme, the intended substrate for $\mathrm{HO}$, only the manganese porphyrins appeared to be degraded to $\mathrm{CO}$ under $\mathrm{HO}$ assay reaction conditions. These findings were unexpected. Closer examination of the test results showed that it was the blank CO production that was suppressed by the presence of the manganese porphyrins. The $\mathrm{CO}$ production in the presence of NADPH was similar to that in the absence of any porphyrin or to that in the presence of non-manganesecontaining porphyrins, either in the presence or absence of NADPH. The blank reaction, for which the NADPH-containing reaction is corrected, represents a minor process of $\mathrm{CO}$ production which has not yet been identified. This process has not been previously observed to be affected by the presence of metalloporphyrin. It could possibly be related to lipid peroxidation processes, which we have found to generate $\mathrm{CO}$ as well as thiobarbituric acid-reactive substances (25). Maines and Kappas (18) found that metalloporphyrins (such as Mn-, Ni-, and SnPP), which do not bind molecular oxygen, cannot be substrates for HO. Although MnPP metabolism has been reported to occur in bacteria (26), there is no evidence of a similar process in mammals (27). If such a process exists, the administration of manganese porphyrins, either as $\mathrm{HO}$ inhibitors or as magnetic reso-

Table 1. In vitro efficacy of manganese and chromium metalloporphyrins*

\begin{tabular}{|c|c|c|c|c|}
\hline \multirow[b]{2}{*}{ Treatment } & \multicolumn{4}{|c|}{$\mathrm{HO}$ activity $(\mathrm{nmol} \mathrm{CO} / \mathrm{mg}$ protein $/ \mathrm{h})$} \\
\hline & Liver & $\begin{array}{l}\text { Remaining activity } \\
\text { (\% of control) }\end{array}$ & Spleen & $\begin{array}{c}\text { Remaining activity } \\
\text { (\% of control) }\end{array}$ \\
\hline $0.1 \mu \mathrm{M}$ & $0.28 \pm 0.09$ & 88 & $1.41 \pm 0.54$ & 89 \\
\hline $\mathrm{I} \mu \mathrm{M}$ & $0.12 \pm 0.04 \dagger$ & 38 & $0.56 \pm 0.25$ & 35 \\
\hline \multicolumn{5}{|l|}{ MnMP } \\
\hline $0.1 \mu \mathrm{M}$ & $0.28 \pm 0.08$ & 88 & $1.25 \pm 0.45$ & 79 \\
\hline $1 \mu \mathrm{M}$ & $0.08 \pm 0.03+t$ & 25 & $0.41 \pm 0.13 \dagger$ & 26 \\
\hline $10 \mu \mathrm{M}$ & $0.06 \pm 0.05 t \ddagger$ & 19 & $0.01 \pm 0.02 \dagger \ddagger$ & 1 \\
\hline $40 \mu \mathrm{M}$ & $0.05 \pm 0.01+\ddagger$ & 16 & $0.00 \pm 0.00+\ddagger$ & 0 \\
\hline \multicolumn{5}{|l|}{ CrPP } \\
\hline \multicolumn{5}{|l|}{ CrMP } \\
\hline $0.1 \mu \mathrm{M}$ & $0.25 \pm 0.13$ & 78 & $0.90 \pm 0.73$ & 57 \\
\hline $1 \mu \mathrm{M}$ & $0.07 \pm 0.05 t \ddagger$ & 22 & $0.08 \pm 0.14$ & 5 \\
\hline $10 \mu \mathrm{M}$ & $0.03 \pm 0.04 t \ddagger$ & 9 & $0.00 \pm 0.00$ & 0 \\
\hline $40 \mu \mathrm{M}$ & $0.01 \pm 0.00 \dagger \ddagger$ & 3 & $0.00 \pm 0.00$ & 0 \\
\hline
\end{tabular}

* Postmitochondrial supernatants from fasted adult male Wistar rat livers and spleens were incubated with the listed concentrations of manganese and chromium metalloporphyrins and $\mathrm{HO}$ assay reagents $(n=3)$. The statistical comparisons are limited to control and to different concentrations of each compound for a given tissue.

$+p<0.05$ compared with controls.

$\ddagger p<0.05$ compared with $0.1 \mu \mathrm{M}$. 


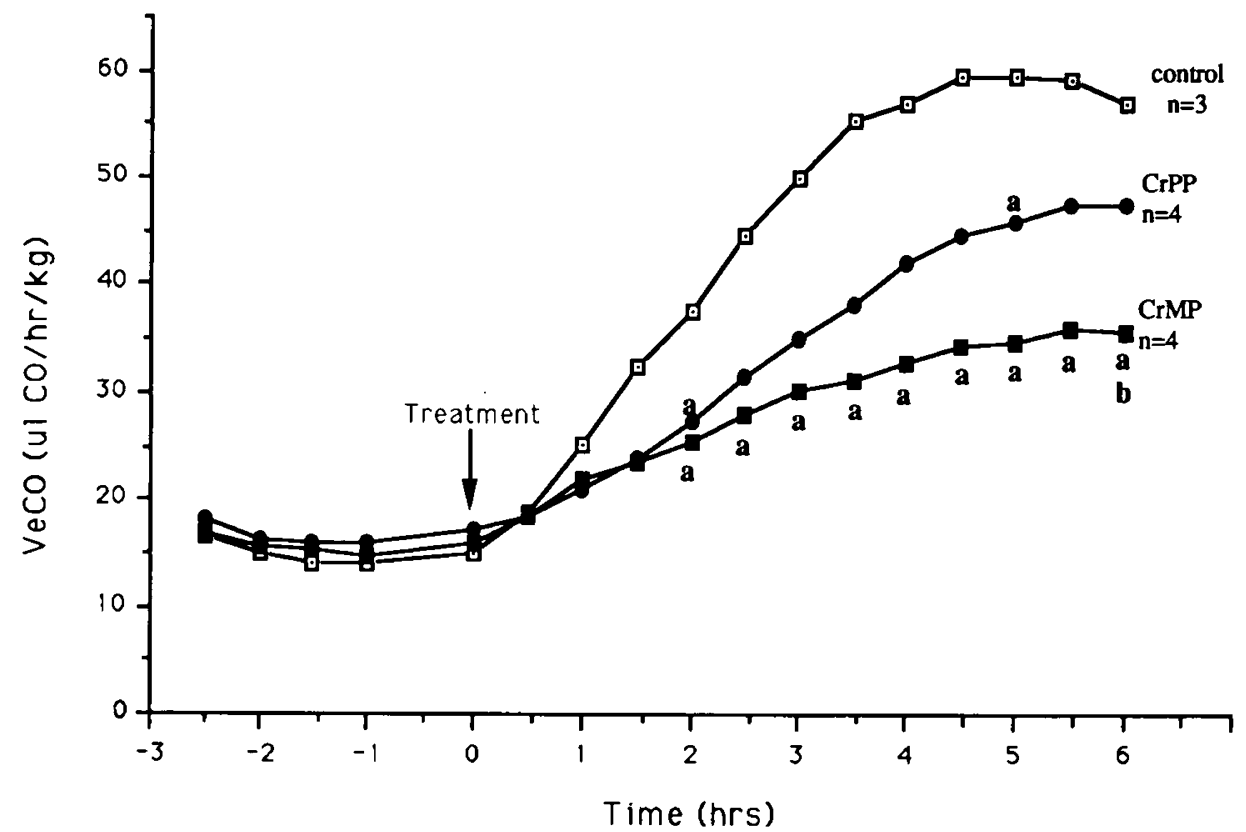

Fig. 5. Effects of CrPP and CrMP on the VeCO of iatrogenic hemolytic rats. VeCO of fasted adult male Wistar rats was monitored for $3 \mathrm{~h}$ before intraperitoneal administration of $30 \mu \mathrm{mol} \mathrm{heme} / \mathrm{kg}$ body wt and $4 \mu \mathrm{mol} \mathrm{CrPP}$ or CrMP/ $\mathrm{kg}$ body wt (Treatment). The VeCO was then monitored for the next $6 \mathrm{~h}$ as indicated. The SD for the data points ranged from 11 to $25 \%, 7$ to $23 \%$, and 1 to $15 \%$ of the mean for the control. CrPP-treated. and CrMP-treated animals, respectively. Significantly different $(p<0.05)$ when compared with control $(a)$ and $\mathrm{CrPP}(b)$ for each time point.

Table 2. In vivo inhibition of rat tissue $\mathrm{HO}$ with chromium porphyrins*

\begin{tabular}{cccc}
\hline & \multicolumn{3}{c}{ HO activity $(\mathrm{nmol} \mathrm{CO} / \mathrm{mg}$ protein $/ \mathrm{h})$} \\
\cline { 2 - 4 } Treatment & Liver & Spleen & Brain \\
\hline Control $(n=4)$ & $2.06 \pm 0.25$ & $3.06 \pm 0.77$ & $0.84 \pm 0.22$ \\
& $(100 \%)$ & $(100 \%)$ & $(100 \%)$ \\
CrPP $(n=4)$ & $0.48 \pm 0.10 \dagger$ & $1.48 \pm 0.86 \dagger$ & $0.86 \pm 0.27$ \\
& $(23 \%)$ & $(48 \%)$ & $(102 \%)$ \\
$\operatorname{CrMP}(n=4)$ & $0.08 \pm 0.06 \dagger \ddagger$ & $0.22 \pm 0.15 \dagger \ddagger$ & $0.87 \pm 0.32$ \\
& $(4 \%)$ & $(7 \%)$ & $(103 \%)$ \\
\hline
\end{tabular}

* The livers. spleens, and brains of the rats described in Figure 5 were tested for $\mathrm{HO}$ activity after death at $t=6 \mathrm{~h}$. The numbers in parentheses denote the level of activity left as a percentage of control activity.

$\dagger p<0.05$ compared with control.

$\ddagger p<0.05$ compared with CrPP.

nance imaging contrast agents, needs to be approached with caution, because the $\mathrm{Mn}^{++}$ion has been shown to be a cardiac toxin, and the $\mathrm{LD}_{50}$ for MnPP was found to be $0.19 \pm 0.01 \mathrm{mM}$ (27). However, our in vivo phototoxicity test did not reveal evidence that manganese porphyrin administration had any noticeable side effects at the concentration tested $(40 \mu \mathrm{M})$. No tests were performed to detect biochemical interferences by these compounds.

Assessment of the photoreactivity of metalloporphyrins, determined from both the photogeneration of CO from NADH and the photodegradation of bilirubin, yielded similar results. Both procedures identified the tin porphyrins as potent photosensitizers, followed by the weaker NiPP. Magnesium PP and the zinc derivatives displayed very slight, but nonsignificant, photoreactivity in these tests. The reported photochemical behavior of zinc porphyrins is not entirely consistent, and ranges from no activity to substantial in vitro photoreactivity $(28,29)$. However, none of the in vivo studies with zinc PP have reported signs of toxicity, chemical or otherwise $(11,15,16)$. The chromium and manganese porphyrins in this study also showed no phototoxicity in vivo.

We have chosen to eliminate from consideration most (except possibly zinc deuteroporphyrin bis glycol) photosensitizing com- pounds because their risk of side effects may not outweigh the benefit of the drug. However, this property may be used in other clinical contexts, $e . g$. in the localization and photodynamic treatment of neoplastic tissues (13) and psoriasis (30). Perhaps, for these purposes, one would select metalloporphyrins with poor $\mathrm{HO}$ inhibition and favorable paramagnetic, pharmacokinetic. and photochemical properties.

In this study, the metalloporphyrins were administered intraperitoneally, because earlier studies have shown that most metalloporphyrins are not readily absorbed when administered orally $(31,32)$. However, Vallier et al. recently showed that the readily soluble zinc deuteroporphyrin bis glycol (33) and CrMP (34) were absorbed enterally by neonatal rats and subsequently inhibited HO activity in liver and spleen. Enteral absorptivity will be a highly desirable quality for an $\mathrm{HO}$ inhibitor intended to inhibit systemic as well as enteral $\mathrm{HO}(35)$. The results in Table 2 indicate that brain $\mathrm{HO}$ activity was not inhibited after intraperitoneal administration of CrPP or CrMP. This is most likely due to the impermeability of the blood brain barrier to those compounds, because $\mathrm{HO}-2$, the predominant isoform in the brain, is inhibitable in vitro by metalloporphyrins (36). Only SnPP has been reported to cross the blood-brain barrier and inhibit $\mathrm{HO}$ activity in vivo (37).

We have chosen the hemolytic model to study the effect of metalloporphyrins, because it is the hyperbilirubinemia caused by hemolysis that needs to be reduced in human neonates (4). Furthermore, we believe that tissue $\mathrm{HO}$, even though it is the rate-limiting enzyme in the heme-degrading pathway, usually occurs in excess relative to the heme available. Thus, in the present rat model most if not all $\mathrm{HO}$ is engaged in the degradation of heme, and it is important to study the effect of metalloporphyrins under this condition.

In summary, the results of this study show that $\mathrm{CrPP}$ and CrMP are potent $\mathrm{HO}$ inhibitors without photoreactive properties. This combination of characteristics makes these compounds attractive for further evaluation as possible agents for the prevention of excessive neonatal jaundice caused by hemolysis. Despite the advantage offered by the nonphotosensitizing metalloporphyrins that have HO inhibitory potency, more research specifically designed to address safety, including pharmacokinetics and 
side effects besides death, would be required before any serious consideration could be given to human experimentation.

Acknowledgments. The authors thank Arthur Tatarov for technical assistance and John J. Mahoney for statistical assistance.

\section{REFERENCES}

1. Landaw SA, Winchell HS, Boone RF 1971 Measurements of endogenous carbon monoxide production in hemolytic disease of the newborn. Clin Res 19:208

2. Smith DW, Cohen RS, Vreman HJ, Yeh A. Sharron S, Stevenson DK 1985 Bilirubin production after supplemental oral vitamin $\mathrm{E}$ therapy in preterm infants. J Pediatr Gastroenterol Nutr 4:38-44

3. Hyman CB, Keaster J, Hanson V 1969 CNS abnormalities after neonatal hemolytic disease or hyperbilirubinemia: a prospective study of 405 patients. Am J Dis Child 117:395-405

4. Newman TB, Maisels MJ 1990 Does hyperbilirubinemia damage the brain of healthy full-term infants? Clin Perinatol 17:331-357

5. Polin RA 1990 Management of neonatal hyperbilirubinemia: rational use of phototherapy. Biol Neonate 58:32-43

6. Tenhunen R. Marver HS, Schmid R 1968 The enzymatic conversion of heme to bilirubin by microsomal heme oxygenase. Proc Nat Acad Sci USA 61:748755

7. Kappas A, Drummond GS. Simionatto CS. Anderson KE 1984 Control of heme oxygenase and plasma levels of bilirubin by a synthetic heme analogue. tin-protoporphyrin. Hepatology 4:336-341

8. Kappas A. Drummond GS, Manola T, Petmezaki S, Valaes T $1988 \mathrm{Sn}$ protoporphyrin use in the management of hyperbilirubinemia in term newborns with direct Coombs-positive ABO incompatibility. Pediatrics 81:485497

9. Maines MD 1988 Heme oxygenase: function. multiplicity, regulatory mechanisms and clinical applications. FASEB J 2:2557-2568

10. Qato MK. Maines MD 1985 Prevention of neonatal hyperbilirubinemia in non-human primates by $\mathrm{Zn}$-protoporphyrin. Biochem J 226:51-57

11. Vreman HJ. Rodgers PA, Stevenson DK 1990 Zinc protoporphyrin administration suppresses iatrogenic hemolytic bilirubin production in rhesus neonates. J Pediatr 117:292-297

12. McDonagh AF, Palma LA 1985 Tin-protoporphyrin: a potent photosensitizer of bilirubin destruction. Photochem Photobiol 42:261-264

13. Moan J 1986 Yearly review: porphyrin photosensitization and phototherapy. Photochem Photobiol 43:681-690

14. Vreman HJ, Gillman MJ, Downum KR. Stevenson DK 1990 In vitro generation of carbon monoxide from organic molecules and synthetic metalloporphyrins mediated by light. Dev Pharmacol Ther 15:112-124

15. Hintz SR, Vreman HJ, Stevenson DK 1990 Mortality after light exposure in metalloporphyrin-treated neonatal rats. Dev Pharmacol Ther 14:187-192

16. Keino H. Nagae H. Mimura S. Watanabe K. Kashiwamata S 1990 Dangerous effects of tin-protoporphyrin plus photoirradiation on neonatal rats. Eur $\mathbf{J}$ Pediatr 149:278-279
17. Drummond GS, Kappas A 1982 Suppression of hyperbilirubinemia in the rat neonate by chromium-protoporphyrin. J Exp Med 156:1878-188.

18. Maines MD, Kappas A 1977 Enzymatic oxidation of cobalt protoporphyrin IX: observations on the mechanism of heme oxygenase action. Biochemistry $16: 419-423$

19. Frydman RB, Tomaro ML. Buldain G, Awruch J. Diaz L. Frydman B 1981 Specificity of heme oxygenase: a study with synthetic hemins. Biochemistry 20:5177-5182

20. V reman HJ, Stevenson DK 1988 Heme oxygenase activity as measured by CO production. Anal Biochem 168:31-38

21. Lowry OH, Rosebrough HJ, Farr AL, Randall RJ 1951 Protein measuremen with the Folin phenol reagent. J Biol Chem 193:265-275

22. Hamori CJ, Vreman HJ, Rodgers PA, Stevenson DK 1989 Zinc protoporphyrin inhibits $\mathrm{CO}$ production in rats. J Pediatr Gastroenterol Nutr 8:110115

23. Vreman HJ, Stevenson DK 1990 Metalloporphyrin-enhanced photodegradation of bilirubin in vitro. Am J Dis Child 144:590-594

24. Rodgers PA, Stevenson DK 1990 The developmental biology of heme oxygenase and inhibition of bilirubin production. Clin Perinatol 17:275-291

25. Vreman HJ, Sanesi, Dennery P. Stevenson DK 1991 Carbon monoxide (CO) as an index of lipid peroxidation. Clin Res 39:109A(abstr)

26. Fuller MD. Caldwell DR 1982 Tetrapyrrole utilization by Bacteroides fragilis Can J Microbiol 28:1304-1310

27. Jackson LS. Nelson JA, Case TA, Burnham BF 1985 Manganese protoporphyrin IX. A potential intravenous paragnetic NMR contrast agent: preliminary communication. Invest Radiol 20:226-229

28. Scott J, Quirke JM, Vreman HJ, Stevenson DK, Downum KR 1989 Metalloporphyrin phototoxicity. J Photochem Photobiol B Biology 7:149-157

29. Greenbaum NL. Kappas A 1991 Comparative photoactivity of tin and zinc porphyrin inhibitors of heme oxygenase: pronounced photolability of the zinc compounds. Photochem Photobiol 54:183-192

30. Emtestam L. Berglund L, Angelin B. Kappas A 1989 Treatment of psoriasis vulgaris with a synthetic metalloporphyrin and UVA light. Acta Derm Venereol 146(suppl): 107-110

31. Drummond GS, Kappas A 1981 Prevention of neonatal hyperbilirubinemia by tin protoporphyrin IX, a potent competitive inhibitor of heme oxidation. Proc Natl Acad Sci USA 78:6466-6470

32. Rosenberg DW, Drummond GS. Kappas A 1989 The in vitro and in vivo inhibition of intestinal heme oxygenase by tin-protoporphyrin. Pharmacology 39:224-229

33. Vallier HA, Rodgers PA, Stevenson DK. Castillo RO 1991 Zinc deuteroporphyrin 2.4 bis glycol is absorbed by the small intestine in neonatal rats. Clin Res 39:18A(abstr)

34. Vallier HA. Rodgers PA. Stevenson DK 1992 Chromium porphyrins inhibit heme oxygenase in neonatal rats. Clin Res 40:23A(abstr)

35. Drummond GS, Rosenberg DW. Kappas A 1992 Intestinal heme oxygenase inhibition and increased biliary iron excretion by metalloporphyrins. Gastroenterology 192:1170-1175

36. Vreman HJ, Lee OK. Stevenson DK 1991 In vitro and in vivo characteristics of a heme oxygenase inhibitor: ZnBG. Am J Med Sci 302:335-341

37. Mark JA. Maines MD 1992 Tin-protoporphyrin-mediated disruption in vivo of heme oxygenase- 2 protein integrity and activity in rat brain. Pediatr Res 32:324-329 